\title{
Microstructure and Properties of TiAIN/a-C Nanocomposite Coatings Prepared by Reactive Sputtering
}

\author{
Masateru Nose ${ }^{1}$, Tokimasa Kawabata ${ }^{2}$, Sara Khamseh $^{3}$, Kenji Matsuda ${ }^{2}$, \\ K. Fujii ${ }^{4}$, Susumu Ikeno ${ }^{2}$ and Wen-An Chiou ${ }^{5}$ \\ ${ }^{1}$ Faculty of Art and Design, University of Toyama, Takaoka 933-8588, Japan \\ ${ }^{2}$ Graduate School of Science and Engineering for Research, University of Toyama, Toyama 930-8555, Japan \\ ${ }^{3}$ Graduate School of Science and Engineering for Education, University of Toyama, Toyama 930-8555, Japan \\ ${ }^{4}$ Industrial Research Institute of Ishikawa, Kanazawa 920-8203, Japan \\ ${ }^{5}$ NanoCenter, 1234 Kim Engineering Building, University of Maryland, College Park, MD20742, U.S.A.
}

TiAlN/a-C nano-composite coatings were synthesized by a reactive co-sputtering process to investigate the effects of sputtering conditions on the microstructure and mechanical properties. Coating films were deposited on square plates of Si and high speed steel (ANSI M2) by the cosputtering of TiAl (pulsed-d.c. sputtering) and C (d.c. sputtering) targets using a "Facing Target-type Sputtering" system at an atmosphere with a mixture of $\mathrm{Ar}$ and $\mathrm{N}_{2}$ but without hydrocarbon gas. The structure of the coatings was investigated by means of XRD, XPS and HRTEM with GIF (Gatan Imaging Filter). Mechanical properties of coating films were measured by a submicron indentation system.

Though TiAlN and a-C coatings showed hardness of about 32 and about $10 \mathrm{GPa}$, respectively, TiAlN/a-C coatings containing 4.6 at $\%$ of $\mathrm{C}$ showed higher hardness of $43 \mathrm{GPa}$. The energy filter images depicted that a change of contrast in the zero-loss image corresponded to nanometer-size of Ti agglomerates in Ti map. C1s spectrum in XPS analysis revealed that carbon in the coatings was bounded as $\mathrm{C}-\mathrm{C}$ and $\mathrm{C}-\mathrm{N}$ without bonding of Ti-C or Al-C. These results indicated that the TiAlN/a-C nano-composite coatings consisted of complicated mixture of nanocrystalline Ti-Al-N phase and a-C phase (including C-N bonding). [doi:10.2320/matertrans.MC200913]

(Received July 30, 2009; Accepted November 13, 2009; Published January 7, 2010)

Keywords: reactive sputtering, TiAlN/a-C, amorphous carbon, nano-indentation, nanocomposite coatings

\section{Introduction}

Transition metal nitrides or carbides are the most widely used coatings for tribological applications such as forming tools or cutting tools. On the other hand, amorphous carbon coatings, such as a-C, a-C:N, or a-C:H [called as diamond like carbon (DLC)], also have been widely applied to machining tools for aluminum, due to improved tribological properties in terms of low friction, high hardness and nonaffinity to work material. However, at temperatures higher than $300^{\circ} \mathrm{C}$, amorphous DLC or a-C changes to graphite and its hardness decreases drastically.

Recent studies of wear-protective coatings have been aiming at exploring multi component systems for improving hardness and/or oxidation resistance. Since Vepřek et al. presented a theoretical concept for the super-hard "nanocomposite" films and their experimental verification on the Ti-Si-N systems, ${ }^{1)}$ nanocomposite coatings composed of crystalline/amorphous nanophases mixture have recently attracted much interest in fundamental research and industrial applications. Nanocomposite coatings consisting of different bonding structure have possibilities of synthesizing a surface protection layer with an unusual combination of mechanical and tribological properties such as high hardness and toughness, superior wear resistance and low frictions. ${ }^{2)}$ To attain this goal, TiC/a-C, ${ }^{3-6)} \mathrm{TiAlN} / \mathrm{C}$ or $\mathrm{CrAlN} / \mathrm{C}$ coatings $^{7-15)}$ have been prepared by various methods, including arc ion plating (AIP), closed field unbalanced magnetron sputtering (CFUBMS), plasma enhanced chemical vapor deposition (PECVD). However, only a limited amount of research on TiAlN/a-C coatings prepared in the mixture of $\mathrm{Ar}$ and $\mathrm{N}_{2}$ gases without hydrocarbon gas has been conducted.
The maximum hardness of TiAlN/a-C coatings synthesized under the atmosphere containing hydrocarbon gas was in the range of 20 to $40 \mathrm{GPa}$, and the hardness is affected by flow rate of the gas. ${ }^{10)}$ XPS analysis of these films showed that some carbon atoms bound as $(\mathrm{Ti}, \mathrm{Al})-\mathrm{C}^{7,12)}$ or $(\mathrm{Ti}, \mathrm{Al})-$ $\mathrm{CN} .{ }^{13)}$ These results indicate that the hardness of TiAlN/a-C coatings is affected not only by microstructure but also by the existence of carbides and the relationship between the microstructure and mechanical property of TiAlN/a-C coatings has not been elucidated satisfactorily.

To study the effect of carbon on the microstructure and mechanical properties of coatings, a series of TiAlN/C coatings has been deposited by a reactive magnetron sputtering of TiAl and carbon targets in a mixture of $\mathrm{Ar}$ and $\mathrm{N}_{2}$. In the previous reports, ${ }^{7,12,13)}$ the films deposited by a reactive sputtering using hydrocarbon gas contain some amount of carbides. In order to eliminate the possible formation of carbide bonding, no hydrocarbon gas was used.

\section{Experiment}

Square of $25 \mathrm{~mm} \times 25 \mathrm{~mm}$ mirror-polished silicon wafers and high-speed steel plates (SKH-51) were used as substrates. All the substrates were cleaned ultrasonically with acetone, ethanol and 2-propanol sequencially before sputtering deposition.

Coating deposition was performed with a reactive sputtering apparatus that has two pairs (TiAl-TiAl and C-C) of targets facing each other (referred to as the "Facing Targettype Sputtering (FTS) system"; Osaka Vacuum Co., Ltd., FTS-2R). Rectangular $(100 \mathrm{~mm} \times 160 \mathrm{~mm} \times 10 \mathrm{~mm}$ thickness) $\mathrm{Ti}_{50} \mathrm{Al}_{50}$ alloy (99.8\%) and carbon (99.9\%) targets were sputtered in a mixture of highly purified argon and nitrogen 
gases (99.9999\%) without hydrogen gas. The system was first evacuated to a vacuum better than $5 \times 10^{-5} \mathrm{~Pa}(=3.8 \times$ $10^{-7}$ Torr) prior to deposition. Based on the result of our previous study of TiAlN film preparation, the flow rate of Ar and $\mathrm{N}_{2}$ gases was fixed at $15 \mathrm{sccm}$ and $20 \mathrm{sccm}$, respectively. The working pressure was kept at $0.15 \mathrm{~Pa}$ (1.1 mTorr). The pulsed d.c. power (frequency; $120 \mathrm{kHz}$, duty cycle; 84\%) and normal d.c. power were supplied to TiAl alloy targets and to carbon targets, respectively. The substrates were heated up to about $200^{\circ} \mathrm{C}$ without applying negative bias voltage during deposition. The deposition rates were about $28 \mathrm{~nm} / \mathrm{min}$ and $0 \sim 6 \mathrm{~nm} / \mathrm{min}$ for TiAlN and C coatings, respectively. Substrates were rotated at $30 \mathrm{rpm}$ during the deposition. The thickness of the TiAlN/a-C composite coating was controlled at about $2.0 \mu \mathrm{m}$ by controlling the sputtering time. Mixing ratio of TiAlN and $\mathrm{C}$ was controlled in the range of $100: 0$ to $83: 17$ (volume fraction) by adjusting incident power of graphite targets. The volume fraction can be monitored from the deposition rate of TiAlN and amorphous carbon coatings.

Composition of coating was analyzed by EPMA (JEOL, JXA-8200D) and quantified with ZAF (Z: atomic number effect, A: Absorption effect, F: Fluorescence excitation effect) correction method without standard samples of carbon and nitrogen. The crystal structure of coatings was identified by an X-ray diffractometer (Philips, X'pert system) using $\mathrm{Cu}$ $\mathrm{K} \alpha$ radiation with $\theta-2 \theta$ or grazing angle mode (GAXRD). The microstructure of coatings was investigated by TEM (TOPCON, EM-002B), HRTEM (JEOL, JEM4010T) equipped with GIF (Gatan Imaging Filter), and XPS (Thermo VG Scientific, Sigma Probe) using $\mathrm{Mg} \mathrm{K} \alpha$ radiation.

Indentation hardness ${ }^{16,17)}$ and effective Young's modulus ${ }^{18)}$ of coatings were measured with a submicron indentation system (Fisher, HC-100XYp) at room temperature using a triangular Berkovitch diamond pyramid. The load was selected to keep an impression depth ratio below $10 \%$ of coating thickness so that the influence of the substrate can be neglected.

\section{Results and Discussion}

Table 1 indicates the chemical composition and the mechanical properties of the TiAlN/C coatings, and the comparison of TiAlN and amorphous carbon (a-C) coatings deposited at the same condition as TiAlN/C coatings. The atomic ratio of $\mathrm{Ti} / \mathrm{Al}$ for all $\mathrm{TiAlN} / \mathrm{a}-\mathrm{C}$ coatings $(\mathrm{S}-1 \sim \mathrm{S}-4)$ was a little higher than that of the target $(\mathrm{Ti} / \mathrm{Al}=0.98)$, the

Table 1 Chemical composition and mechanical properties of the TiAlN/C coatings.

\begin{tabular}{lccccccc}
\hline \multirow{2}{*}{$\begin{array}{c}\text { Sample } \\
\text { No. }\end{array}$} & $\begin{array}{c}\text { Mixed } \\
\text { ratio } \\
(\text { vol\%C) }\end{array}$ & Ti & Al & N & C & $\begin{array}{c}\text { Composition (at\%) } \\
\text { Hardness } \\
H_{\mathrm{pl}}(\mathrm{GPa})\end{array}$ & $\begin{array}{c}\text { Moung's } \\
E^{*}(\mathrm{GPa})\end{array}$ \\
\cline { 5 - 8 } S-1 & 0 & 24.9 & 24.5 & 50.6 & - & 32.1 & 286 \\
\hline S-2 & 6 & - & - & - & - & 33.0 & 275 \\
\hline S-3 & 9 & 23.0 & 22.0 & 50.5 & 4.6 & 43.2 & 265 \\
\hline S-4 & 17 & 20.5 & 19.8 & 51.1 & 8.5 & 22.0 & 198 \\
\hline a-Carbon & - & - & - & - & - & 10.0 & 94 \\
\hline
\end{tabular}

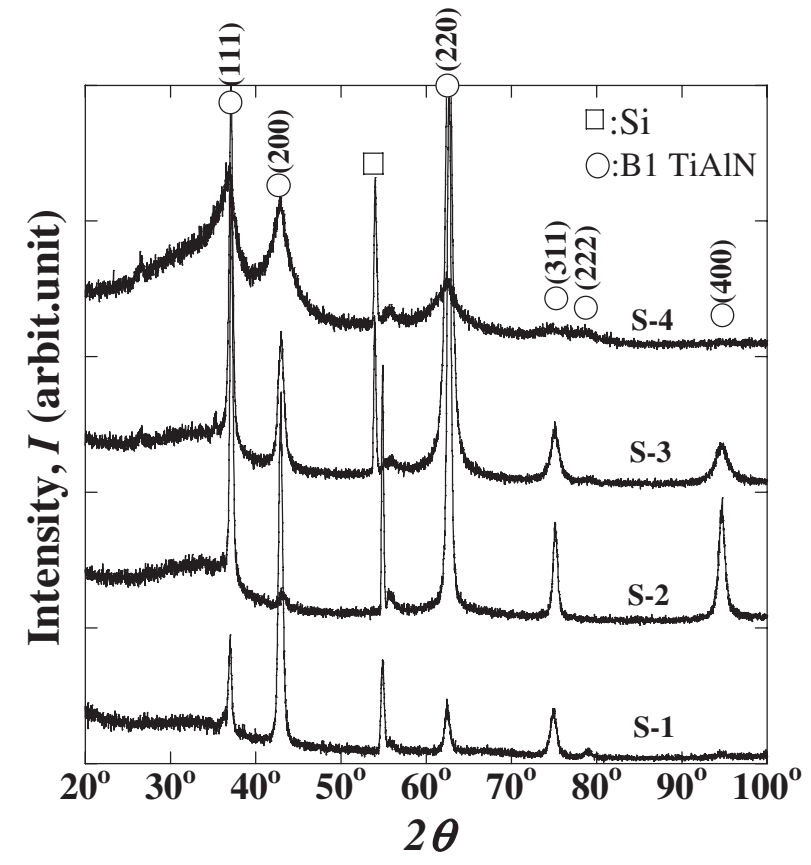

Fig. 1 Development of XRD patterns for TiAlN(C) coatings containing different amounts of carbon measured by grazing angle method.

ratio was kept between 1.02 and 1.05 . Nitrogen content of coatings was kept in the range of 50 to 52 at\%. TiAlN (S-1) and a-C coatings has hardness of $32 \mathrm{GPa}$ and $10 \mathrm{GPa}$, respectively. A small amount of carbon addition (about $6 \mathrm{vol} \%$ ) increased hardness a little in spite of low hardness of a-Carbon. However, TiAlN/9 vol\%C (= 4.6 at\%) (S-3) coating shows the highest hardness (about $43 \mathrm{GPa}$ ). With additional amount of a-C, the hardness of $\mathrm{S} 4$ coating ( 8.5 at $\%)$ was decreased to $22 \mathrm{GPa}$. On the contrary, Young's modulus decreased monotonically with increasing carbon addition. Especially, the Young's modulus of S-3 coating is decreased from $287 \mathrm{GPa}$ to $265 \mathrm{GPa}$ by the addition of 4.6 at $\%$ C. Note that high hardness with low Young's modulus is the characteristic of nanocomposite coating. ${ }^{1)}$ From these results, we decided to investigate the difference in microstructure and properties of S-1, S-3 and S-4 coatings.

Figure 1 shows glancing angle incidence XRD patterns of TiAlN and TiAlN/a-C coatings containing different concentration of carbon. Only one phase of the cubic B1 NaCl type structure was observed excepting the peak from substrate (Si). A drastic change of main peaks of B1-TiAlN from (200) in S-1 coating to (111) and (220) in S-2 coating indicates that a small amount of carbon addition (about 6 vol\% of carbon) appears to change the preferred orientation of the coating. With further increment of carbon content (S-3, S-4), TiAlN peaks become broader. Dark-field TEM micrographs reveals that crystal grain size decreases with the increases of carbon content (Fig. 2). Figure 3 illustrates grain size measurement based on dark-field TEM micrographs of in plan views and XRD peak width. As for the TiAlN/4.6 at\%C coating, grain sizes measured from dark-field TEM of cross-sectional view were added in the Fig. 3. These results revealed that grain sizes decrease monotonically with an increase of carbon content. The grain width of TiAlN/4.6 at $\% \mathrm{C}$ coating measured from dark-field TEM of cross-sectional views is about 


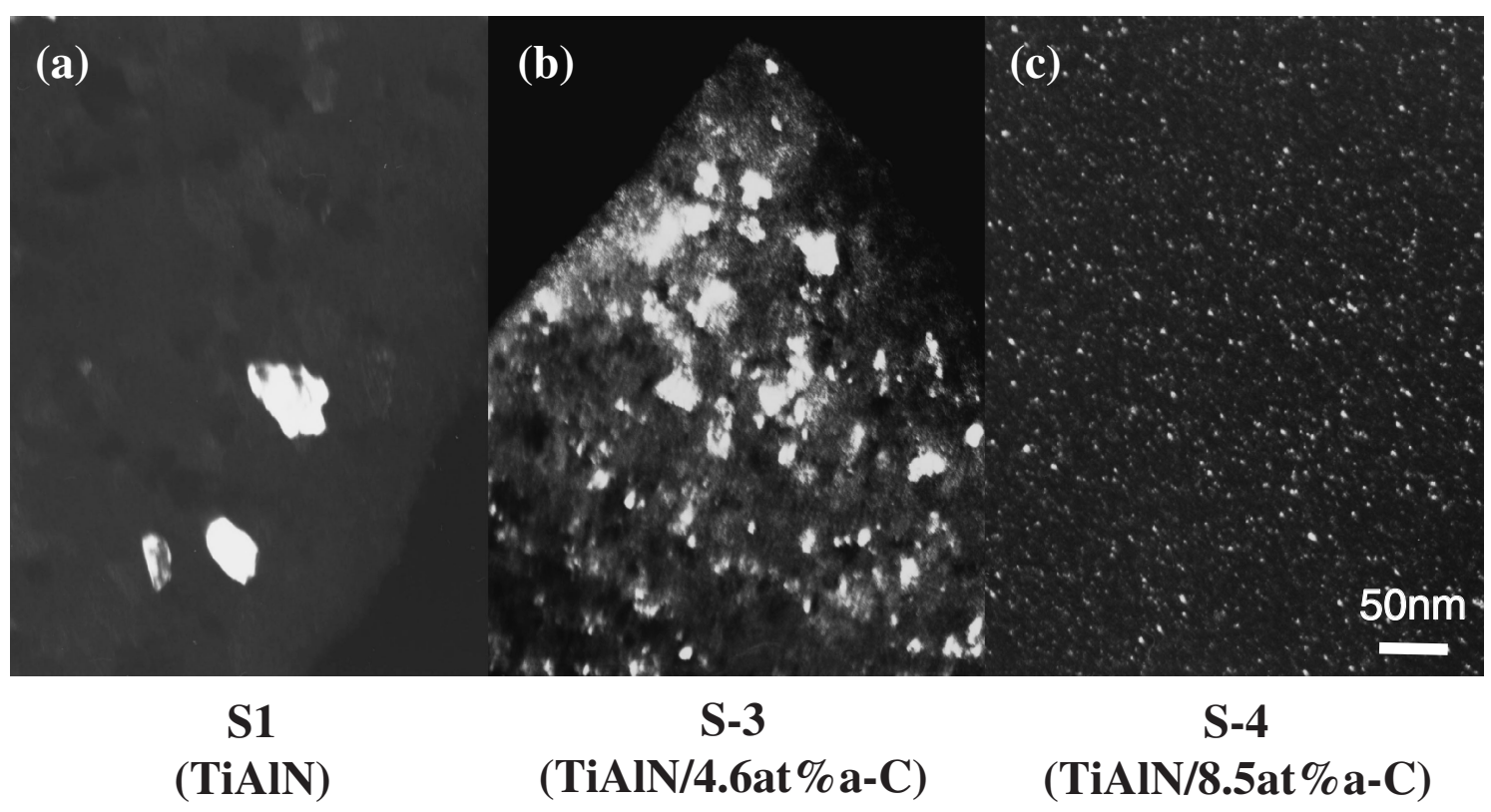

Fig. 2 Plan-view TEM micrographs of TiAlN (a), TiAlN/4.6 at\%C (b) and TiAlN/8.5 at\%C (c) coatings.

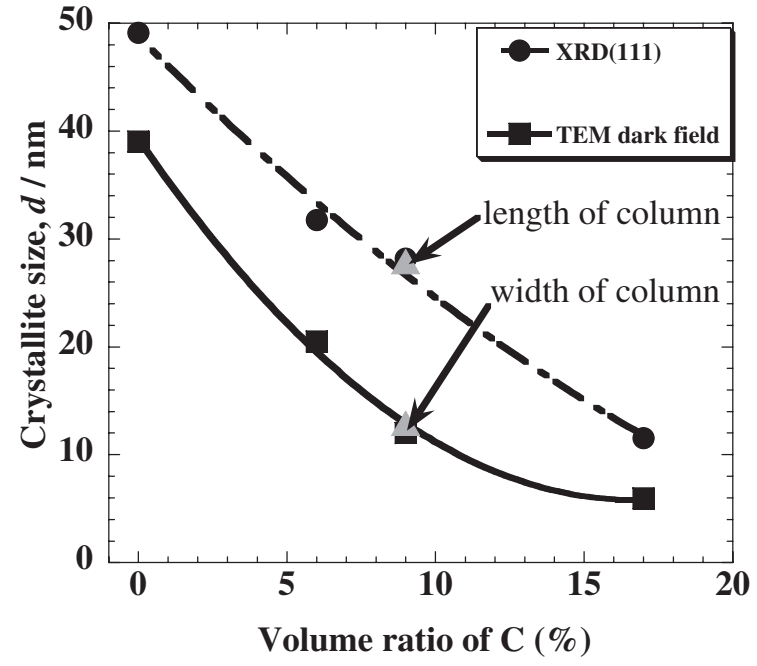

Fig. 3 Dependence of the average crystallite size determined from the XRD and dark filed TEM micrographs on the carbon volume fraction in the coating.

$10 \sim 12 \mathrm{~nm}$, which is consistent with the size measured from plan-view, and the grain length measured from cross-sectional views is in good agreement with the size estimated from XRD peak width.

TEM observation reveals the strong correlation between the carbon content, grain size and morphology in more detail (Figs. 4 to 7). A plan-view TEM image and SAED (selected area electron diffraction) pattern of TiAlN $/ 4.6$ at $\% \mathrm{C}$ coatings shows the single phase of the TiAlN B1-NaCl type structure with the grain size of about $10 \mathrm{~nm}$. No other crystalline phase was found (Fig. 4(a)). Figure 4(b) depicts an HRTEM planview image of TiAlN $/ 4.6$ at $\% \mathrm{C}$ coating. Areas surrounded by dotted line in the figure indicate a typical example of amorphous like phase in the film. It is obvious that TiAlN grains in the range of $5 \sim 10 \mathrm{~nm}$ are surrounded by amorphous like phase.
Figure 5(a) shows the bright-field TEM image and electron diffraction pattern of a cross-sectional view of TiAlN/a-4.6\% C coatings. The diffraction pattern does not exhibit strong preferred orientation. The diameter of columns was decreased with additional carbon as compared with TiAlN coatings. For an example, the averaged column width of TiAlN and TiAlN/4.6 at\%C were about $40 \mathrm{~nm}$ and about $10 \mathrm{~nm}$, respectively. TiAlN columnar grain of about $10 \mathrm{~nm}$ in width and over $20 \mathrm{~nm}$ in length, which is so-called "nanocolumn", is observed in Fig. 5(b) (TiAlN/4.6 at\%C). In the case of cross-sectional view TEM samples, as more than several columns overlap along the incident direction of electron beam, amorphous-like phase between TiAlN grains is not observed clearly.

Figure 6(a) shows a plan-view TEM image of TiAlN/ 8.5 at $\% \mathrm{C}$ coatings and the corresponding SAED pattern. The monotonic contrast with numerous small high electron dense (dark) particles and diffused halos in the electron diffraction pattern indicated the coexistence of amorphous and nanocrystalline materials in the coating. HRTEM image of TiAlN/8.5 at $\% \mathrm{C}$ coating also reveals nano-crystallites circles dispersed throughout in the amorphous matrix (Fig. 6(b)). Although the carbon content in TiAlN/8.5 at\% coating is similar to that of Ti-Al-N-C coatings in the range of 9.5 to $13.5 \% \mathrm{C}$ reported by M. Steuber et al., ${ }^{12)}$ the microstructure revealed by TEM was completely different. Instead of partially diffused SAED pattern and "fibre-like structure (average column diameter is about $50 \mathrm{~nm}$ for $13.5 \% \mathrm{C}$ coatings)" found by them, the diffused broad SAED pattern with dispersed nano-crystallites in amorphous matrix was observed in this study. Further investigation is required to fully understand the microstructure difference between these reports.

Figure 7 depicts energy filter TEM (EFTEM) images of the plan-view sample of TiAlN/4.6 at\%C. As can be seen in the Fig. 7, several nanometer size of agglomerates were observed both in the Zero-loss image (Fig. 7(a)) and Ti map 


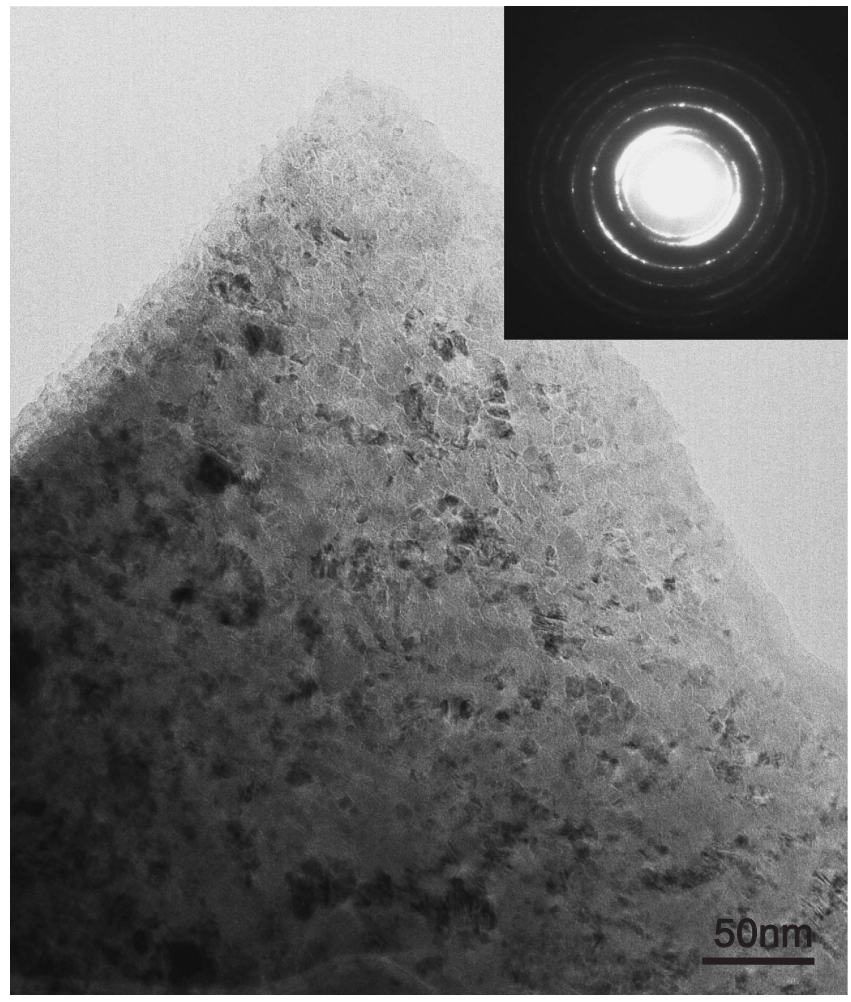

(a)

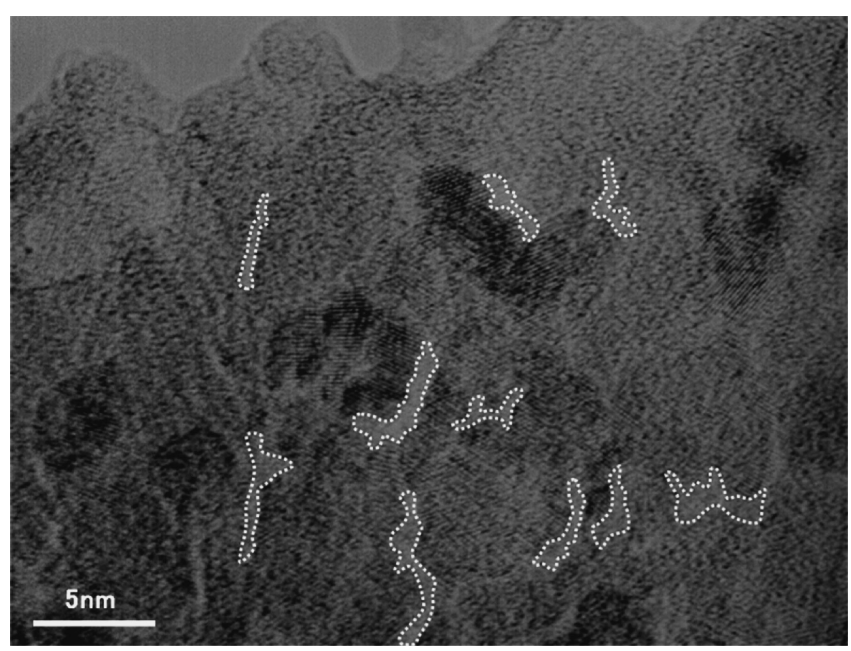

(b)

Fig. 4 (a) Plan-view TEM micrograph and SAED pattern of TiAIN/ 4.6 at $\% \mathrm{C}$ coatings. (b) HRTEM plan-view image of TiAlN/4.6 at\%C coating.

(Fig. 7(b)). They indicate that a change of contrast in zeroloss image accompanies the change of composition of Ti. On the other hand, as $\mathrm{C}$ and $\mathrm{N}$ maps only with a relatively homogeneous distribution were obtained. However, the spaces among the agglomerates are in the range of $1 \sim 2 \mathrm{~nm}$, which correspond to the amorphous like areas in Fig. 4(b).

To minimize the adventitious carbon contamination, the outermost surface of the coating was removed using $\mathrm{Ar}^{+}$ion beam etching for $1.8 \mathrm{ks}$ prior to XPS analysis. Figure 8 depicts the XPS C1s and N1s spectrum of TiAlN/4.6 at\%C. In the N1s spectrum, three components were revealed and assigned to the binding energies of $396 \mathrm{eV}, 398.1 \mathrm{eV}$ and

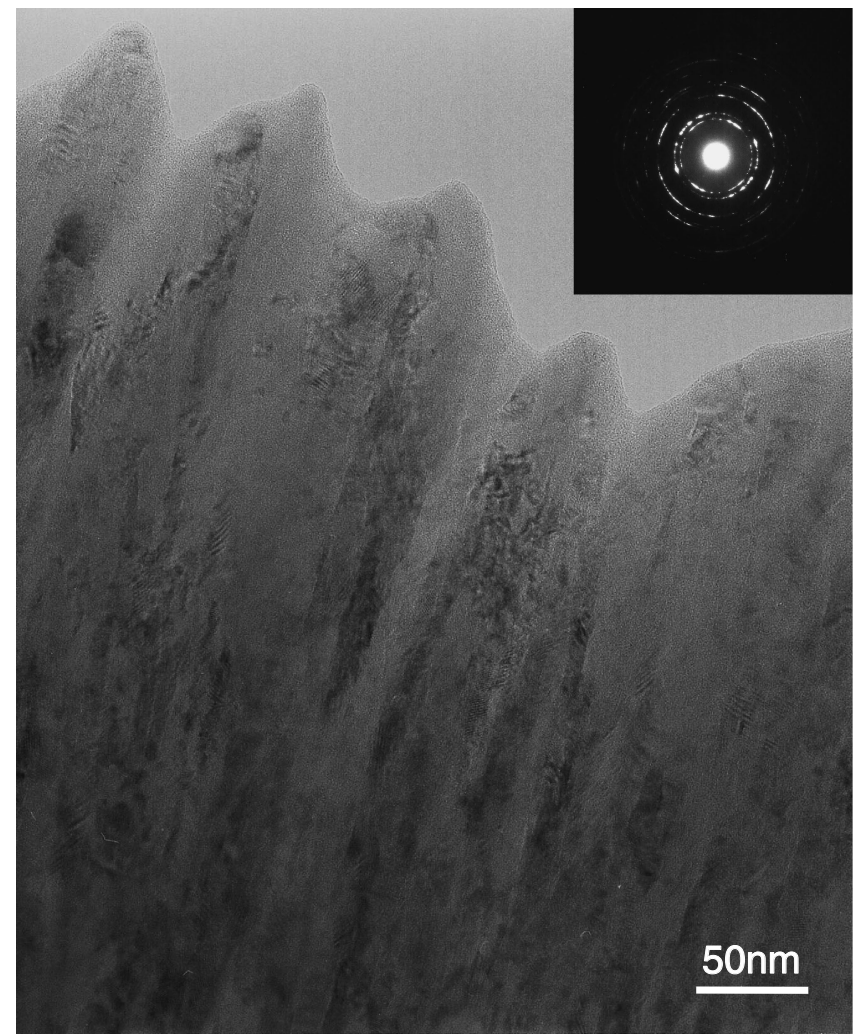

(a)

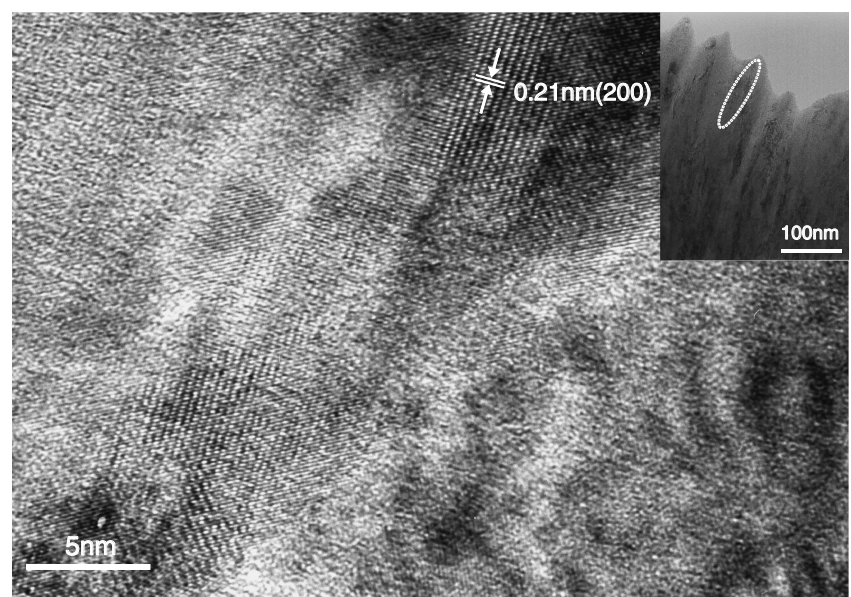

(b)

Fig. 5 (a) Cross sectional view TEM micrograph and SAED pattern of TiAlN/4.6 at $\% \mathrm{C}$ coatings. (b) HRTEM cross sectional view image of TiAlN/4.6 at $\% \mathrm{C}$ coating.

$401.9 \mathrm{eV}$, respectively. The curve fitting analysis indicated that the first component is $\mathrm{N}-(\mathrm{Ti}, \mathrm{Al})$ and the second component is $\mathrm{N}-\mathrm{C} \mathrm{sp}^{2}$. But, the last component is unclear, which is likely to be organic $\mathrm{N}-\mathrm{C}$ bonding. This result revealed that nitrogen bound mostly with transition metals $(396 \mathrm{eV})$ and with carbon $(398.1 \mathrm{eV})$. Analysis of C1s spectrum revealed that carbon in the coatings bound almost as $\mathrm{C}-\mathrm{C}(284.4 \mathrm{eV})$ with some bondings of C-N sp ${ }^{2}(285.9 \mathrm{eV})$ and $\mathrm{C}-\mathrm{N} \mathrm{sp}{ }^{3}$ or $\mathrm{C}-\mathrm{O}(288.3 \mathrm{eV})$. In the $\mathrm{C} 1 \mathrm{~s}$ spectrum, there is no evidence for bondings of Ti-C or Al-C $(281.3 \sim 282 \mathrm{eV})$.

Stueber et al. reported that 5 bands at 281.8, 283.7, 285.5, 286.5 and $287.9 \mathrm{eV}$ were fitted in the $\mathrm{C} 1 \mathrm{~s}$ spectrum of 


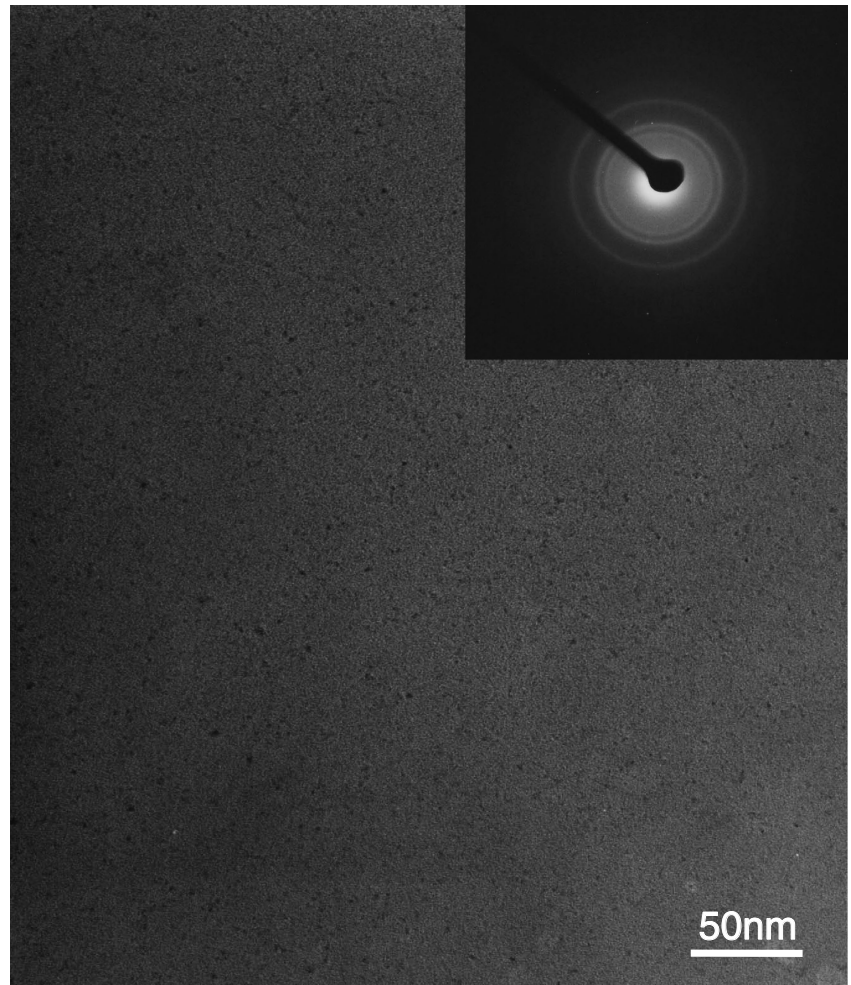

(a)

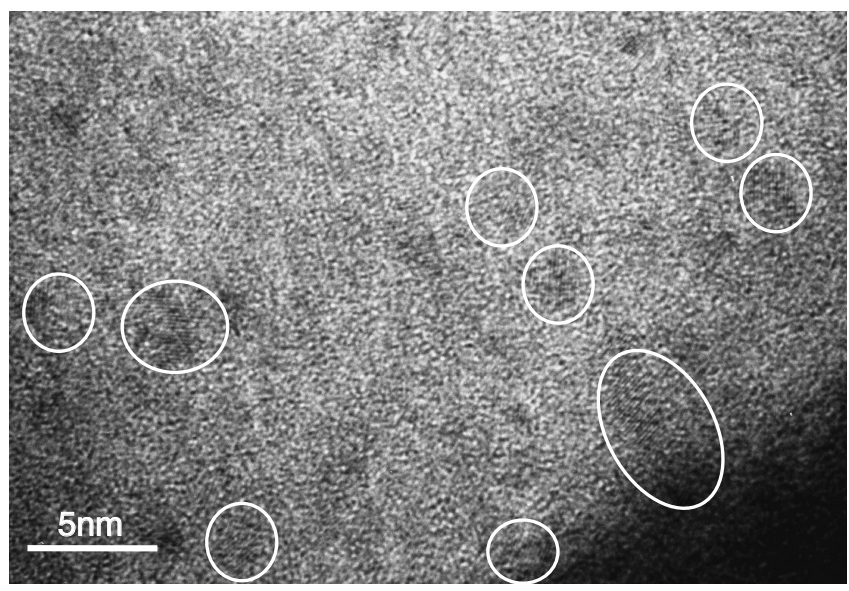

(b)

Fig. 6 (a) Plan-view TEM micrograph and SAED pattern of TiAlN/ 8.5 at $\%$ C coatings. (b) HRTEM plan-view image of TiAlN $/ 8.5$ at $\% \mathrm{C}$ coating.

TiAlN/28 at $\% \mathrm{C}$ coating deposited by reactive magnetron sputtering of a TiAl target in a mixture of $\mathrm{Ar}, \mathrm{N}_{2}$ and $\mathrm{CH}_{4}$ gases. According to their result, the peak at $281.8 \mathrm{eV}$ or $285.5 \mathrm{eV}$ was stronger than others, and the former peak was attributed to Ti-C bonding and the latter one was to $\mathrm{C}-\mathrm{OH}$ bonding. They kept substrate temperature at $400^{\circ} \mathrm{C}$ and bias voltage at $-80 \mathrm{~V}$. On the other hand, in this study, the coatings were deposited with $\mathrm{TiAl}$ and carbon targets at $200^{\circ} \mathrm{C}$ in the mixed gases of only $\mathrm{Ar}$ and $\mathrm{N}_{2}$. The different bonding state of the TiAlN/a-C coatings perhaps attributed to the difference in the sputtering condition, especially to the difference in the carbon source.

Based on these considerations, we can conclude that nanocomposite structure consisting of complicated mixture of

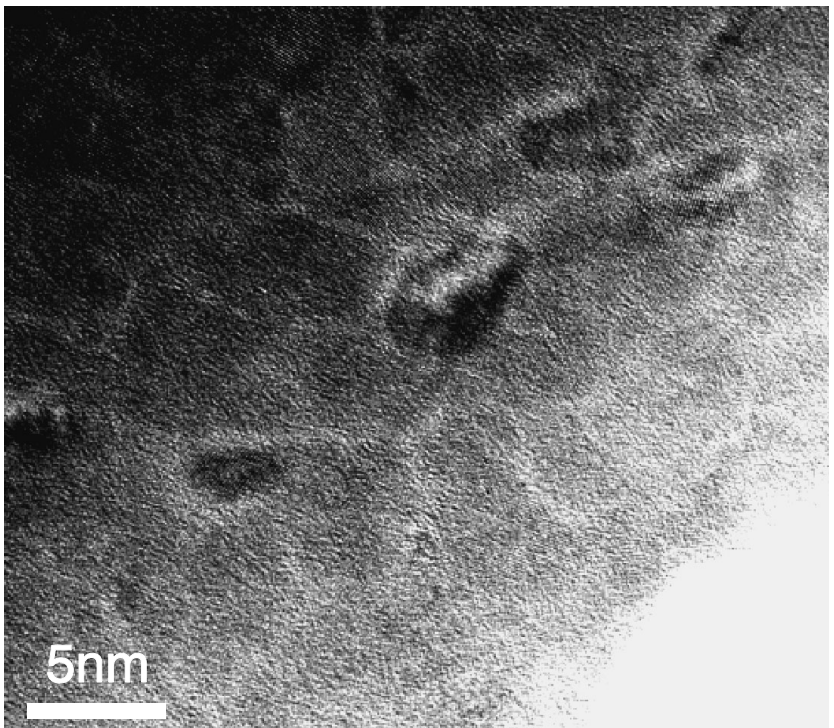

(a)

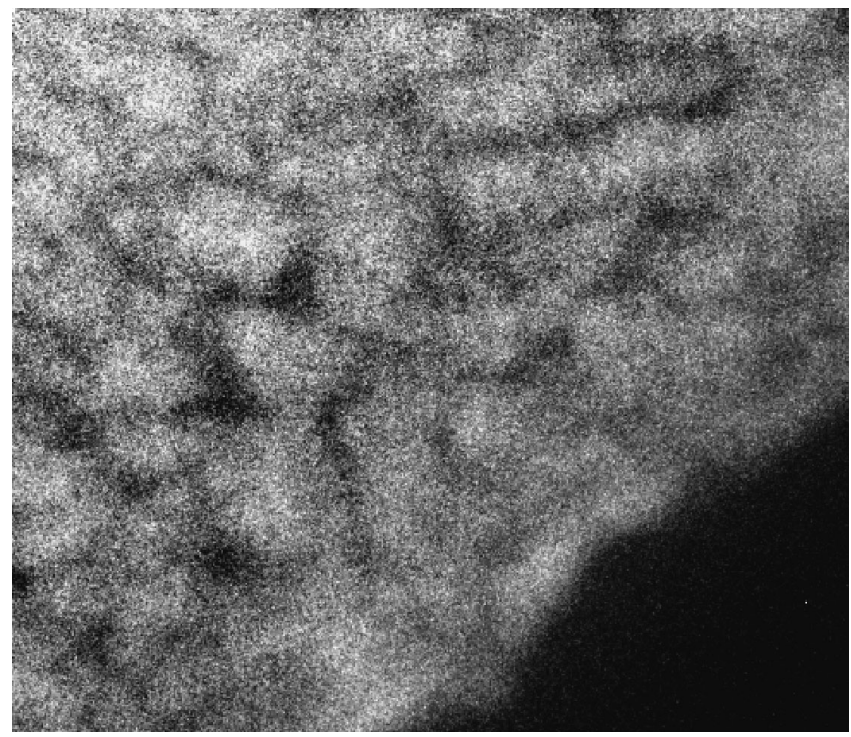

(b)

Fig. 7 EF-TEM images of a plan-view sample for TiAlN/4.6at\%C coating: zero-loss image (a), Ti elemental map (b).

nanocrystalline Ti-Al-N and amorphous carbon phase (with a small amount of $\mathrm{C}: \mathrm{N}$ phase) existed in the TiAlN/a-C coatings.

\section{Conclusions}

TiAlN/a-C coatings have been prepared by pulsed d.c. and d.c reactive sputtering using 2 sets of TiAl and carbon targets in the FTS system. Evaluation of mechanical properties by submicron indentation and microstructure study of these coatings using XRD, HRTEM, EFTEM and XPS have drawn the following conclusions: The indentation hardness and the effective Young's modulus increase with the addition of a about 9 vol\% (4.6 at\%) carbon without applying a bias voltage to the substrate. The hardness of TiAlN/a-C coatings reaches a maximum of $43 \mathrm{GPa}$ for $4.6 \mathrm{at} \% \mathrm{C}$ coating. On the other hand, Young's modulus decreased from 287 to $265 \mathrm{GPa}$ 


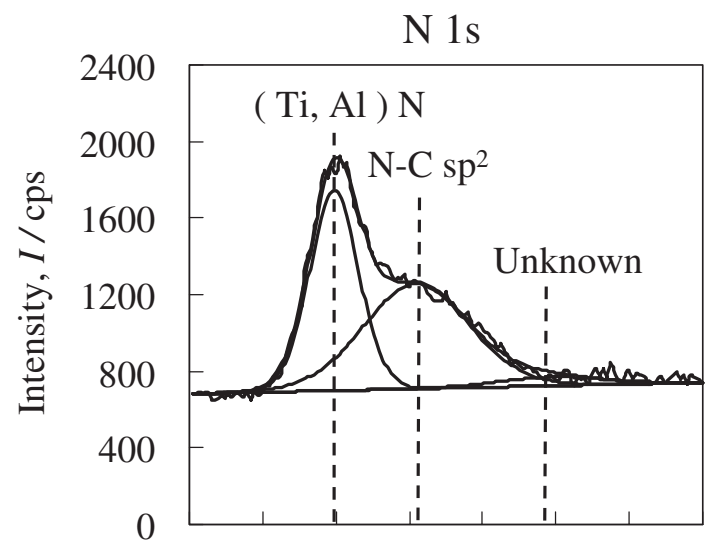

392394396398400402404406 Energy, $E / \mathrm{eV}$

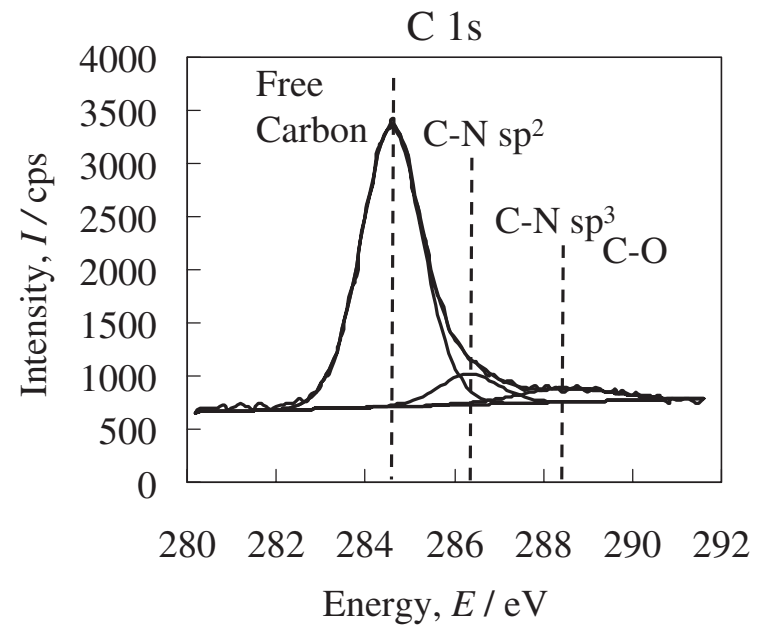

Fig. 8 XPS C1s and N1s spectra for TiAlN/8.5 at\%C coating.

from 0 to 4.6 at $\%$ C. The HRTEM image and Ti map of EFTEM revealed that TiAlN nanocolumns were embedded in an amorphous like phase. Furthermore, XPS analyses indicated that carbon atoms in the coating have $\mathrm{C}-\mathrm{C}$ bonding mainly with small amount of $\mathrm{C}-\mathrm{N}$ bonding without any bonding of metal carbide. Accordingly, TiAlN/C coating is a nanocomposite coating that consists of a mixture of nanocrystalline Ti-Al-N and amorphous carbon (with a small amount of C-N phase).

\section{Acknowledgements}

This work was supported partly by a grant for scientific research from Japan Society for the Promotion of Science (JSPS). The authors would like to express their deep gratitude to Ms. Juli-Ma, who was a graduate student of University of Toyama for carrying out the sample preparation.

\section{REFERENCES}

1) S. Vepřek and S. Reiprich: Thin Solid Films 268 (1995) 64-71.

2) H. A. Jehn: Surf. Coat. Technol. 131 (2000) 433-440.

3) T. Zehnder and J. Patscheider: Surf. Coat. Technol. 131 (2000) 433440.

4) D. Galvan, Y. T. Pei and J. Th. M. De Hosson: Acta Mater. 53 (2005) 3925-3934.

5) Y. T. Pei, D. Galvan and J. Th. M. De Hosson: Acta Mater. 53 (2005) 4505-4521.

6) S. Zhang, X. L. Bui and X. Li: Diamond Relat. Mater. 15 (2006) 972976.

7) J. Shieh and M. H. Hon: J. Vac. Sci. Technol. A 20 (2002) 87-92.

8) S. Zhang, Y. Fu, H. Du, X. T. Zeng and Y. C. Liu: Surf. Coat. Technol. 162 (2002) 42-48.

9) E. Lugsheider, K. Bobzin and K. Lackner: Surf. Coat. Technol. 174175 (2003) 681-686.

10) J. M. Lackner, W. Waldhauser, R. Ebner, R. J. Baller, T. Schöberl and B. Major: Thin Solid Films 468 (2004) 125-133.

11) J. M. Lackner, W. Waldhauser, R. Ebner, J. Keckés and T. Schöberl: Surf. Coat. Technol. 177-178 (2004) 447-452.

12) M. Stueber, P. B. Barna, M. C. Simmonds, U. Albers, H. Leiste, C. Ziebert, H. Holleck, A. Kováca, P. Hovsepian and I. Gee: Thin Solid Films 493 (2005) 104-112.

13) Y. Z. Huang, M. Stueber and P. Hovsepian: Appl. Surf. Sci. 253 (2006) 2470-2473.

14) J. Petter, T. Ishikawa and N. Shima: Plasma Process. Polym. 4 (2007) s668-s672.

15) M. Nose, T. Kawabata, M. Ohi, T. Nagae, S. Masa, Y. Hatano, S. Ikeno and K. Nogi: Polymer 4 (2007) s681-s686.

16) W. C. Oliver and G. M. Pharr: J. Mater. Res. 7 (1992) 1564-1583.

17) International Standard, ISO 14577-1, First edition (2002) pp. 1-25.

18) J. Musil, H. Zeman, F. Kunc and J. Vlček: Mater. Sci. Eng. A 340 (2003) 281-285. 